\title{
A Brief Achievements of SENAI CIMATEC Against COVID-19
}

\section{Leone Peter Andrade ${ }^{1 *}$}

${ }^{I}$ Editor-in-Chief and Director of Integrated Campus of Manufacturing and Technology (CIMATEC); Salvador, Bahia, Brazil

In this brief, we summarized some actions that the SENAI CIMATEC did from March to June 2020, and continues to promoting against the COVID-19 pandemic. We know we have the knowledge to combat and be adapted to this crisis.
March 2020 (Figures 1 and 2)

- Presentations and workshops about the pandemic and a guidance to the SENAI CIMATEC community.

Figure 1. Folder 1 - Actions and activities of SENAI CIMATEC against COVID-19 (March 2020).

\section{Informe Sistema FIEB $\mathbf{n}^{\circ} \mathbf{1}$}

O Sistema FIEB tem atuado no enfrentamento da crise gerada pelo novo coronavírus. Confira algumas ações:

\section{Aquisição de equipamento para diagnóstico da Covid-19}

Para apoiar no diagnóstico da Covid-19, doença

causada pelo novo coronavirus, o SENAI CIMATEC

está implantando, no Instituto SENAI de Inovação em Saúde, equipamentos e protocolos para realizar testes que detectam o novo coronavírus. Os testes serão disponibilizados para o público industrial e também para aumentar a capacidade da rede pública.

A máquina de termociclador em tempo real Quantistudio

1 , usada para ensaios de PCR, está em implantação

no SENAI CIMATEC. A previsão é de que o exame PCR

- considerado um dos mais assertivos no diagnóstico -

comece a ser realizados em duas semanas.

O SESI Bahia ficará responsável pela coleta dos materiais nas indústrias para realização dos testes. Além disso, o SENAI CIMATEC vai oferecer suporte técnico para outros dois equipamentos que o Estado está adquirindo.

\section{Manutenção de respiradores mecânicos}

Para apoiar os hospitais públicos, o SENAI CIMATEC, junto com parceiros industriais, deu início a um projeto para aumentar a disponibilidade de respiradores mecânicos na rede hospitalar. O equipamento é necessário para os casos mais graves da doença, que afeta o sistema respiratório, causando falta de ar.

O projeto é voltado para a manutenção dos equipamentos fora de operação, para garantir que as máquinas existentes na rede hospitalar estejam prontas para uso, em caso de necessidade.

O SENAI CIMATEC fará o levantamento dos equipamentos quebrados / descalibrados que precisam de manutenção. Um time de técnicos está sendo preparado para esta iniciativa e o laboratório do SENAI CIMATEC estará disponivel para efetuar a manutenção e executar projetos de peças para fabricação rápida.

\section{Captação de recursos para compra de respiradores} mecânicos

Ainda sobre os respiradores mecânicos, a Federação das Indústrias do Estado da Bahia (FIEB) está organizando a captação de recursos junto a empresas do setor industrial baiano para a compra de respiradores mecânicos.

\section{R NAVÍRUS}

Com a iniciativa, a entidade busca apoiar o Estado no enfrentamento do novo coronavírus.

Linha de envase de álcool no SENAI CIMATEC Park Uma linha de produção para fracionamento e envase de álcool líquido $70 \%$ está sendo montada no SENAI CIMATEC PARK. Na estrutura, serão envasadas as doações de álcool líquido que o governo do estado vem recebendo. A iniciativa é realizada em parceria com duas empresas industriais e Governo do Estado, por meio das secretarias do Planejamento (SEPLAN) e de Desenvolvimento Econômico (SDE), e conta com o apoio do Corpo de Bombeiros. O álcool liquido envasado no SENAI CIMATEC PARK será distribuído para hospitais públicos e privados, além de UPAs e farmácias de manipulação.

SESI Bahia articula uso das escolas da rede para campanha de vacinação

O SESI Bahia articula com a Prefeitura de Salvador o uso das escolas da entidade, cujas aulas estão suspensas desde o último dia 18, para a vacinação de idosos contra influenza e sarampo. O objetivo é mitigar os riscos de as filas se transformarem em possíveis focos de propagação do vírus.

Sindicato de Açúcar doa 160 mil litros de álcool 70\% Em apoio ao Estado da Bahia, o SINDAÇUCAR está doando 160 mil litros de álcool 70\%, através das suas usinas associadas Agrovale (Juazeiro), Santa Maria (Medeiros Neto) e Santa Cruz (Santa Cruz Cabrália). Também estão doando álcool $70 \%$ para os colaboradores, unidades de saúde, hospitais, lares de idosos, igrejas, instituições e organizações sociais das cidades onde as empresas estão sediadas. E, seguindo a determinação do Governo Federal (MP 926), as atividades de produção e distribuição não serão interrompidas.

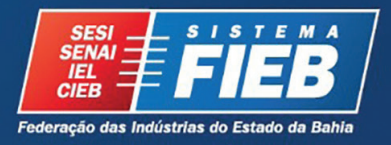

Received on 2 March 2020; revised 9 June 2020.Address for correspondence: Dr. Leone Peter Andrade. Centro Universitário SENAI CIMATEC. Av. Orlando Gomes, 1845, Piatã. Zip Code: 41650-010. Salvador, Bahia, Brazil. E-mail: leone@fieb.org.br.

J Bioeng. Tech. Appl. Health 2020;3(1):3-11. (0) 2020 by SENAI CIMATEC. All rights reserved. 
Figure 2. Folder 2 - Actions and activities of SENAI CIMATEC against COVID-19 (March 2020).

\section{Informe Sistema FIEB $n^{\circ} 2$}

Confira algumas ações do Sistema FIEB para o

enfrentamento da crise provocada pelo novo coronavírus:

\section{CAMPANHA ARRECADA RECURSOS PARA COMPRA DE EQUIPAMENTOS HOSPITALARES}

O IEL Bahia, em parceria com outras entidades do setor empresarial baiano, coordena uma campanha de arrecadação de recursos para compra de equipamentos hospitalares necessários para o diagnóstico e tratamento da Covid-19.

Realizada na plataforma de crowdfunding Bloxs, a campanha tem como objetivo arrecadar $\mathbf{R} \$ 2$ milhões, com a participação e contribuição de empresários, entidades empresariais e da sociedade baiana.

O valor arrecadado será gerido e empregado por um grupo de entidades empresariais, para compra de equipamentos como respiradores mecânicos, peças para manutenção de respiradores mecânicos, testes rápidos de Covid-19 e EPIs para profissionais de saúde.

As doações devem ser efetuadas no site

bloxs.com.br/campanha/bahia-contra-covid19, onde também é possível encontrar as regras da campanha de arrecadação, além de outras informações.

\section{RESPIRADORES MECÂNICOS PASSAM POR MANUTENÇÃO} NO SENAI CIMATEC

Cerca de 50 respiradores mecânicos já estão no SENA CIMATEC para passar por manutenção. $O$ intuito da iniciativa é aumentar o número de equipamentos disponiveis na rede de saúde do estado para o enfrentamento da pandemia de coronavírus. $O$ aparelho é necessário para os casos mais graves da doença, que afeta - sistema respiratório, causando falta de ar.

A ação teve início no último final de semana, com o

levantamento dos equipamentos que precisam de manutenção. Até a quinta-feira, 26.03, mais de 160 foram identificados.

Além da manutenção, o SENAI BA também é responsável
C.M. RAVIRUS

pela logística de recolhimento e entrega dos aparelhos, além de buscar peças para manutenção com empresas parceiras. Antes do serviço de manutenção, os ventiladores mecânicos passam por um processo de desinfecção.

A iniciativa do SENAI BA foi adotada pelo Departamento Nacional do SENAI e se tornou um programa nacional, que conta com a parceria do Ministério da Economia, do Ministério da Saúde e de outras entidades.

\section{SUPERCOMPUTADOR INSTALADO NO SENAI CIMATEC} SERÁ UTILIZADO EM PESQUISAS SOBRE O CORONAVÍRUS O supercomputador OGBON, instalado no SENAI CIMATEC será utilizado para realizar simulações em alta velocidade durante pesquisas sobre o novo coronavírus. Mais de $50 \%$ da capacidade de processamento do supercomputador será destinada para apoiar projeto de pesquisa de uma universidade norte-americana que analisa como o coronavírus se comporta no corpo humano e acompanha a evolução da doença. $O$ estudo pretende abrir caminho para o desenvolvimento de remédios e vacinas.

- OGBON é resultado de uma parceria entre o Centro de Pesquisa e Desenvolvimento Leopoldo Américo Miguez de Mello (Cenpes) e o SENAI CIMATEC. Com capacidade de processamento de 1.605 PFlops, o equipamento foi adquirido por meio de um projeto de pesquisa da Petrobras, com recursos da Agência Nacional do Petróleo, Gás Natural e Biocombustíveis (ANP). Ele integra o Centro de Supercomputação para Inovação Industrial do SENAI CIMATEC, que conta com cinco supermáquinas.

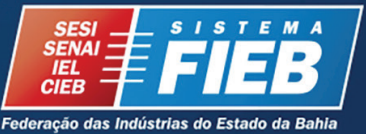

- Creation of a COVID-19 contingency plan for the SENAI CIMATEC workers.

- More than 80 projects were contemplated by ISI (SENAI Institute for Innovation in Advanced Health Systems) to help to preventing, diagnosing and treating COVID-19:

o Using new technologies of industry 4.0 against COVID-19.

o Expansion of the number of ventilators.

o In addition to expanding the test network, researchers at SENAI CIMATEC have been implanted a new diagnostic method (approved by World Health Organization) for faster and more effective detection of the new coronavirus
(SARS-CoV-2) with the results in 30 minutes.

o Creation of new image diagnostic methods through Artificial Intelligence.

o Development of rapid tests and personal protective equipment (PPE) that can replace masks, gloves and soaps.

o Replacement of pieces and components used in intensive care units (ICUs).

- Opening of distance education courses on industry 4.0 during the pandemic.

- Provision of state-of-the-art laboratories to assist the State of Bahia, Brazil, with carrying out RT-PCR tests for the coronavirus, with fast and accurate results (Figure 3 ). 
- Mitigation of risks related to the coronavirus through the availability of vaccination of the elderly against influenza and measles.

- Fundraising for the purchase of hospital materials.

- Acquisition of diagnostic equipment for COVID-19 (assembly of a molecular biology laboratory for the diagnosis of COVID-19 through the RT-PCR exam within the infrastructure of state-of-the-art laboratories at CIMATEC).

April 2020 (Figures 4 and 5)

- Fundraising for the purchase of mechanical ventilators.
Figure 3. Molecular biology laboratory implemented by CIMATEC to carry out RT-PCR tests on industry professionals from the State of Bahia (Brazil).

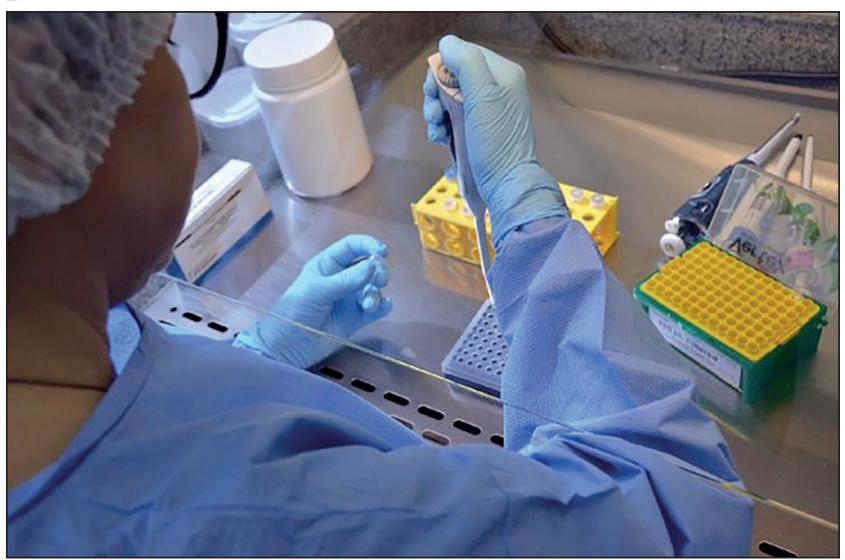

Figure 4. Folder 3 - Actions and activities of SENAI CIMATEC against COVID-19 (April 2020).

\section{Informe Sistema FIEB $\mathbf{n}^{\circ} \mathbf{3}$}

Confira algumas ações do Sistema FIEB para o enfrentamento da crise provocada pelo novo coronavírus:

CAPTAÇÃO DE RESPIRADORES E LOGÍSTICA DO SENAI BAHIA VIABILIZAM MANUTENÇÃO DE VENTILADORES

Desde o dia 23 de março, profissionais do SENAI Bahia

mapeiam as instituiç̋̃es que poderiam necessitar da

recuperação de ventiladores pulmonares. Eles entram em contato com Unidades de Pronto Atendimento (UPA), unidades de saúde e hospitais, dando prioridade para as instituições públicas, além de providenciarem a retirada e a entrega dos respiradores.

Outra força tarefa, formada por engenheiros e técnicos do SENAI Cimatec e de outras instituições, corre contra o tempo para disponibilizar os aparelhos que estavam fora de uso. Nem todos estão em condições de conserto, mas, até o dia 02 de abril, 21 equipamentos já tinham sido recuperados. A expectativa é que, com a ação, voltem à utilidade 120 ventiladores.

Como o SENAI Bahia tem unidades na maioria das cidades do interior, essa capilaridade facilita o mapeamento e coleta dos respiradores mecânicos em todo o estado, além da devolução dos aparelhos. Além de Salvador, já foram atendidas unidades de saúde em mais de 30 municípios. Um e-mail foi disponibilizado pelo SENAI BAHIA para que as instituições de saúde possam solicitar o serviço, que está sendo feito de

forma gratuita. $\mathrm{O}$ contato deve ser feito por meio do faleconoscosenaiba@fieb.org.br.

MINISTÉRIOS PÚBLICOS E FIEB UNIDOS PARA ELEVAR PRODUÇ̃̃O DE ÁLCOOL GEL

O Ministério Público do Trabalho (MPT), o Ministério Público estadual (MP-BA) e a FIEB estão unindo esforços para

sensibilizar as empresas industriais baianas a direcionarem suas linhas de produção para a fabricação de álcool em gel ou líquido. Empresas com capacidade para adequar sua linha de produção podem obter de forma rápida e desburocratizada a autorizaçãoo da Agência Nacional de Vigilância Sanitária (Anvisa).

Um comunicado informando as regras simplificadas para a obtenção da autorização está sendo distribuída às indústrias que poderiam ajustar suas plantas para atender à grande demanda do mercado. A indústria interessada deverá encaminhar e-mail para gimep@anvisa.gov.br, solicitando autorização especial para produção de álcool líquido ou gel, com pedido de excepcionalidade, acompanhado da documentação necessária.

\section{R. NAVÍRUS}

61 MIL PEÇAS DE VESTUÁRIO PARA HOSPITAIS SÃo PRODUZIDAS PELO SETOR DE CONFECÇÃO

Os hospitais da rede pública de saúde do estado começaram a receber, na primeira semana de abril 2,5 mil conjuntos de roupas para médicos e enfermeiros e 3,5 mil camisolas para pacientes. As peças de vestuário estão sendo produzidas por empresários baianos do setor de confecções. A ação é fruto da parceria entre a Secretaria de Desenvolvimento Econômico (SDE), Secretaria do Planejamento do Estado da Bahia (Seplan), o Sindicato da Indústria de Vestuário e Artefatos de Joalheria e Bijuteria do Estado da Bahia (Sindvest), e o Condomínio Bahia Têxtil.

A iniciativa vai ajudar a suprir a demanda por enxovais hospitalares, que aumentou com expansão da rede de atendimento em saúde, em função do enfrentamento ao coronavírus. Por outro lado, a medida contribui para manter 25 empresas participantes em atividade. A parceria prevê a confecção de 61 mil itens de vestuário, sendo 7,2 mil lençóis, 7 mil camisolas, 40 mil roupas privativas, compostas por calça tipo pijama e camisa, e 7,2 mil toalhas de banho, de uso hospitalar. Mas já há um pedido extra de mais 8 mil peças. Com a parceria, é possível adaptar e continuar parte da produção, mantendo a economia baiana ativa.

\section{PESQUISADORES DO SENAI CIMATEC UTILIZAM}

INTELIGÊNCIA ARTIFICIAL PARA ESTUDOS SOBRE 0 CORONAVÍRUS

O centro de competência em Inteligência Artificial do CIMATEC, um dos braços do Centro de Supercomputação para Inovação Industrial da instituição (CS2I), está desenvolvendo pesquisas próprias relacionadas ao coronavírus. Uma delas é sobre o suporte ao diagnóstico de Covid-19 em exames de Raio-X e Tomografia Computadorizada. 
Figure 5. Folder 4 - Actions and activities of SENAI CIMATEC against COVID-19 (April 2020).

\section{Informe Sistema FIEB $n^{\circ} 4$}

Confira algumas ações do Sistema FIEB para o enfrentamento da crise provocada pelo novo coronavírus:

\section{SESI E SINDUSCON INICIAM BLITZ CONTRA A COVID-19} Parceiros históricos nas ações de saúde e segurança no trabalho voltadas para a indústria da construção, o SESI e o Sinduscon Bahia começam, nesta semana, uma ação conjunta para prevenir a incidência de Covid-19 nos canteiros de obra da Bahia. Trata-se da Blitz contra a Covid-19. A medida tem inicialmente como alvo uma população de mais de cinco mil trabalhadores da construção que estão em atividade em 41 canteiros de obras que já aderiram à iniciativa.

A parceria prevê visitas aos canteiros para realizar ações preventivas de saúde e também para orientar sobre o cumprimento do Ofício

Circular SEI n. 1088, do Ministério da Economia, que trouxe

orientações para as empresas de construção diante da pandemia do coronavírus.

Na área de saúde, o SESI realizará a medição da temperatura corporal bem como orientação e esclarecimento de dúvidas sobre a Covid-19.

O presidente do Sinduscon-BA, Carlos Marden Passos, lembrou da parceria histórica. "O SESI tem uma longa história de parceria com a indústria da construção e vai nos ajudar a orientar as empresas e atuar na prevenção junto aos trabalhadores da construção",

acrescentou.

O superintendente do SESI Bahia, Armando Neto, destaca que "neste momento de crise, a entidade não podia deixar as empresas do sindicato sem um apoio". Ele destaca que as ações estão sendo definidas em conjunto com os líderes do sindicato para a visita da blitz aos canteiros indicados pelo Sinduscon.

\section{SENAI CIMATEC E SESI VÃO APLICAR 13.800 TESTES PCR EM} TRABALHADORES DA INDÚSTRIA

Numa ação de enfrentamento à pandemia de Covid-19, o SENAI CIMATEC vai realizar testes de PCR em trabalhadores da indústria que apresentem sintomas da doença. Serão feitos 13. 800 exames, a partir do dia 15 de abril.

A iniciativa será realizada em parceria com o SESI, que irá até as empresas interessadas, na capital e no interior do estado, e fará a coleta de material oral e nasal no trabalhador sintomático.

Em seguida, o conteúdo será trazido até o Instituto SENAI de Inovação em Sistemas Avançados de Saúde (ISI SAS), no SENAI CIMATEC, onde foi montado um Laboratório de Diagnóstico Molecular exclusivo para testes da Covid-19. Lá, as amostras serão processadas (etapas de extração, amplificação e diagnóstico). Os resultados são emitidos em cerca de quatro horas após recebimento das amostras.

"Montamos aqui um laboratório nível de segurança NB2, ou seja, com condições adequadas para trabalho com amostras infecciosas, para realizar este teste, que é o que vem sendo feito em todos os

laboratórios de referência do país, a exemplo do Lacen", explica a gestora do ISI em Sistemas Avançados em Saúde do CIMATEC, Cleide Guedes.

\section{H. NAVÍRUS}

Testes PCR - Este exame é considerado um diagnóstico molecular padrão ouro, aprovado pela Organização Mundial de Saúde - para o diagnóstico do novo coronavírus. Do material que foi coletado, uma pequena amostra genética é extraída de forma automatizada e amplificada num termociclador. Então, é possivel atestar a presença do RNA do vírus.

"De forma resumida, o teste RT-qPCR, conhecido como PCR em tempo real, é um teste de diagnóstico molecular altamente sensível que consegue identificar a presença do novo coronavírus (SARS-CoV2) nas amostras coletadas dos trabalhadores com suspeita da Covid-19", afirma a pesquisadora do ISI SAS do CIMATEC, Bruna Machado.

SENAI CIMATEC PRODUZ "ESCUDOS FACIAIS" PARA DOAR A PROFISSIONAIS DE SAÚDE

Cerca de mil protetores ou escudos faciais (face shields) estão sendo produzidos por dia no SENAI CIMATEC PARK, localizado em Camaçari. A unidade montou uma pequena fábrica para confeccionar o produto, essencial à proteção dos profissionais de saúde que atendem pacientes com a Covid-19. A estimativa é que sejam produzidas 10 mil máscaras faciais.

O equipamento de proteção individual, que funciona como uma barreira entre o profissional e o paciente, está em falta tanto na rede pública como na rede privada de saúde. E a escassez é generalizada: os Estados Unidos e países da Europa, por exemplo, também sofrem com a falta do material de proteção. Como consequência, um número cada vez maior de profissionais de saúde é infectado pelo vírus.

IEL REALIZA LIVES SOBRE CARREIRA E MERCADO DE TRABALHO O IEL está realizando lives, via Instagram, com profissionais das áreas de Psicologia e Marketing. O objetivo é trabalhar temas sobre desenvolvimento pessoal e mercado de trabalho em meio à crise gerada pela pandemia de Covid-19, a fim de que profissionais de qualquer idade se reinventem antes do retorno das atividades normais. A programação prossegue nos dias 14 e 22 de abril. Dia 14 , às 14 horas, o tema é “Um novo mercado de trabalho está surgindo. Como desenvolver e reconhecer as habilidades essenciais para este novo cenário?", com Afonso Monteiro. Já no dia 22.04, também às 14h, a live é sobre "Você é a sua melhor marca. Marketing pessoal: atitudes que fazem diferença na crise", com Ana Carla.

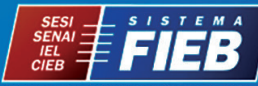

- Enabling maintenance of pulmonary ventilators (Figure 6).

- Production of face shield masks for hospitals in Salvador, Bahia, Brazil (industrial conversion).

- Use of the OGBON supercomputer in partnership with a North American universities to analyze the behavior and evolution of the new coronavirus pandemic as well as high-speed simulations for the epidemiology of the disease.

- Use of Artificial Intelligence for new COVID-19 detection methods using x-Rays and Computed Tomography (CT).

- Production and packing of gel alcohol for distribution in industries and hospitals in the
Figure 6. Maintenance of pulmonary ventilators.

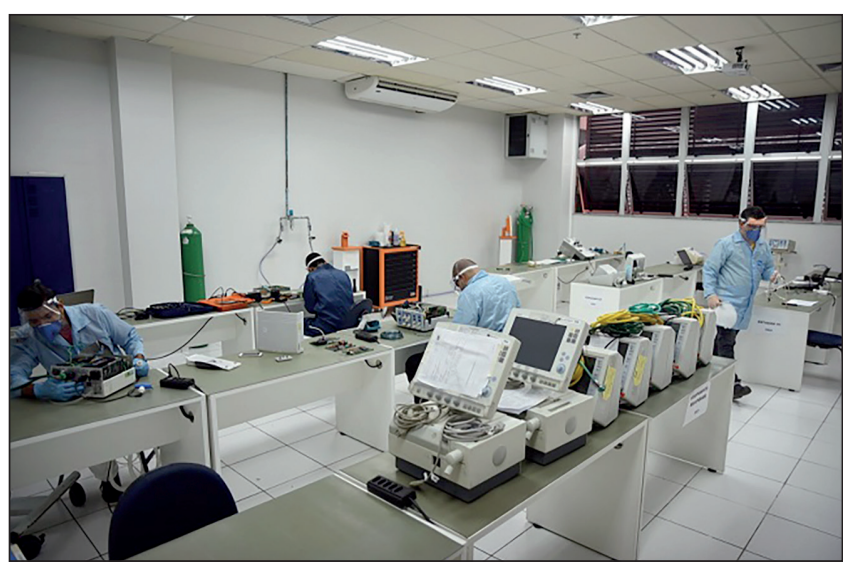


State of Bahia, Brazil (industrial conversion) (Figure 7).

- Preparation and distribution of a Guidance to inform companies for preventing COVID-19 in the industrial sector.

- Application of RT-PCR tests to industry workers from all over the State of Bahia, Brazil (more than 13,800 tests).

- The clothing sector produced 61 hospital garments.

May 2020 (Figures 8 and 9)

- Compliance of industries to the new guidelines, mainly for the food sector to
Figure 7. Production and packing of gel alcohol for distribution to industries and hospitals in the State of Bahia, Brazil (industrial conversion).

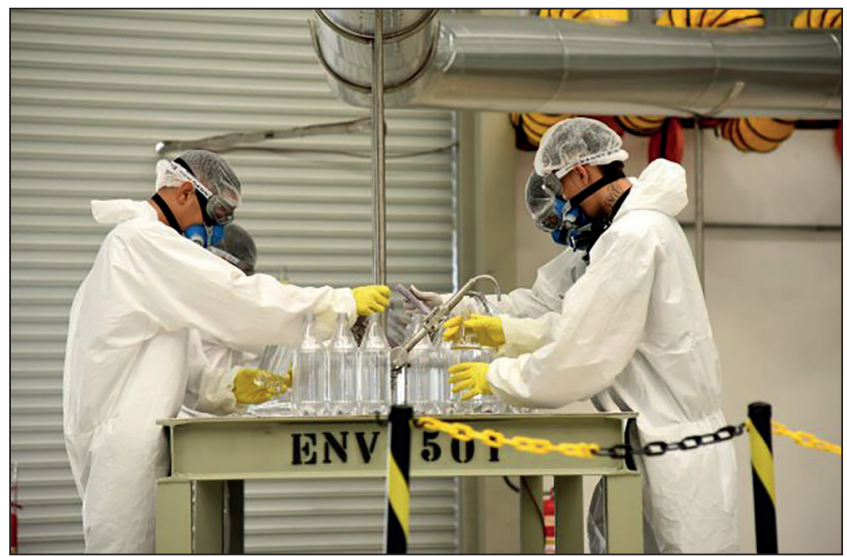

Figure 8. Folder 5 - Actions and activities of SENAI CIMATEC against COVID-19 (May 2020).

\section{Informe Sistema FIEB $n^{\circ} 5$}

Confira algumas ações do Sistema FIEB para o enfrentamento da crise provocada pelo novo coronavírus:

SENAI CIMATEC DESENVOLVE TÚNEL DE DESINFECÇÃO

Um túnel de desinfeção foi desenvolvido pelo SENAI CIMATEC com o objetivo de combater a contaminação e proliferação do novo coronavírus. Baseado em projetos internacionais, o túnel metálico mede 2,5 metros e tem um sistema de distribuição hidráulica que espalha microjatos de uma solução de água e hipoclorito de sódio (água sanitária), durante a passagem de pessoas pelo

equipamento.

Em fase experimental, o túnel será testado no Hospital Espanhol, uma das unidades de tratamento para coronavírus em Salvador. A ideia é que os profissionais de saúde passem pelo túnel antes de retirar os equipamentos de proteção individual (EPIS), momento em que estão mais vulneráveis à contaminação.

SESSENTA RESPIRADORES PULMONARES FORAM RECUPERADOS $O$ trabalho de recuperação de respiradores pulmonares, realizado pelo SENAI Bahia e SENAI CIMATEC, já conseguiu devolver em operação, até o (dia 22.04), 60 aparelhos para cerca de 20 instituições entre hospitais, unidades de Emergência e Pronto Atendimento da capital e do interior. Além da capital, 12 municípios já foram beneficiados com a ação.

O trabalho de recuperação dos aparelhos é feito por uma equipe formada por engenheiros e técnicos do SENAI CIMATEC e das empresas Ford e GPE, que correm contra o tempo para disponibilizar 120 aparelhos que estavam fora de uso. Como o SENAI-BA tem unidades na maioria das cidades do interior, essa capilaridade facilita o mapeamento e coleta dos respiradores mecânicos em todo o estado, além da devolução dos aparelhos.

Além da Bahia, os pontos de manutenção gratuita existem em 18 estados. Em âmbito nacional, a expectativa é de que sejam consertados entre 3.500 e 4 mil aparelhos por técnicos e voluntários capacitados pelo SENAI CIMATEC para o serviço.

\section{CANTEIROS DE OBRAS PASSAM POR BLITZ CONTRA A} COVID-19

A Blitz contra a Covid-19, uma iniciativa do SESI-BA e do Sinduscon-BA, já foi realizada em 25 canteiros de obra em

Salvador, Candeias e Vitória da Conquista, envolvendo 1.500 trabalhadores do setor da construção civil nestes municípios. $\mathrm{Na}$ iniciativa, as equipes, compostas por engenheiros, técnicos de enfermagem e enfermeiros do trabalho, realizam ações

\section{R NAVÍRUS}

preventivas de saúde e orientam sobre o cumprimento do Ofício Circular SEI número 1247, do Ministério da Economia, direcionado às empresas de construção diante da pandemia do novo coronavírus.

Iniciadas em Salvador, no dia 14.04, as blitze têm atualmente 45 canteiros de obras inscritos em todo o estado. A estimativa que cerca de cinco mil trabalhadores da indústria sejam envolvidos. A expectativa do SESI e do Sinduscon é que mais empresas da construção façam adesão à iniciativa.

Além do Sinduscon, outros sindicatos da indústria estão procurando o SESI para ampliar a realização das blitze em outros segmentos. Estão previstas visitas a indústrias vinculadas ao Sindvest de Feira de Santana, Sindvest Salvador e Simagran. As blitze também serão realizadas nas 550 empresas participantes do Programa SESI Viva+ em toda Bahia. Além disso, a iniciativa será realizada na região oeste do estado, em parceria com a Associação Baiana dos Produtores de Algodăo (Abapa).

SENAI CIMATEC DOA MAIS DE 12 MIL "ESCUDOS FACIAIS" Mais de 12 mil escudos faciais (face shields) produzidos no SENAI CIMATEC Park, em Camaçari, já foram doados a hospitais, Unidades de Pronto Atendimento (UPA), corporações e secretarias de estado da Bahia e também para o estado do Amapá. As máscaras face shield serão utilizadas por profissionais da área de saúde e de outros serviços essenciais, a exemplo dos bombeiros, durante o combate à pandemia de coronavírus. Com investimento interno de $\mathbf{R} \$ 120 \mathrm{mil}$, a instituição pretende produzir $\mathbf{2 0}$ mil protetores faciais, até que o fornecimento seja regularizado pelas indústrias.

Cerca de mil escudos faciais (face shields) estão sendo produzidos por dia em uma pequena fábrica montada no SENAI CIMATEC Park para confeccionar o produto, que é um equipamento de proteção individual (EPI). Parte do material produzido (cerca de 300 máscaras) foi encaminhada para a capital do Amapá. Os escudos faciais vão ajudar a reforçar a proteção contra o coronavírus.

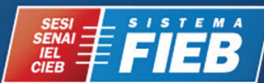


Figure 9. Folder 6 - Actions and activities of SENAI CIMATEC against COVID-19 (May 2020).

\section{Informe Sistema FIEB $n^{\circ} 6$}

Confira algumas ações do Sistema FIEB para o enfrentamento da crise provocada pelo novo coronavírus:

FIEB PROMOVE LIVES SOBRE TEMAS DE INTERESSE DA INDÚSTRIA Referências para a indústria na área de relações trabalhistas, o empresário Alexandre Furlan e o consultor Homero Arandas foram os convidados da live promovida pela FIEB, na terça-feira, dia 28.04, no canal da entidade no Instagram, com o tema $O$ que muda nas relações de trabalho?. A iniciativa faz parte da série Diálogos FIEB, que vai discutir temas relevantes para o setor industrial.

Durante a live, eles abordaram as questões judiciais e o papel do governo para reduzir tensões nas relações trabalhistas, além de apresentar o posicionamento do setor produtivo.

Alexandre Furlan é presidente do Conselho de Relações do Trabalho da Confederação Nacional da Indústria (CNI) e vice-presidente da Organizaçăo Internacional dos Empregadores (OIE) para a América Latina. Já Homero Arandas, que há mais de 30 anos atua como negociador patronal em acordos coletivos de trabalho, na solução de conflitos trabalhistas e no desenvolvimento de equipes, é presidente do Conselho de Relações Trabalhistas da FIEB e membro do Conselho Temático de Relações do Trabalho e Desenvolvimento Social da CNI. A próxima live será realizada no dia 5 de maio, às $18 \mathrm{~h}$, com o deputado Eduardo Salles, presidente da Frente Parlamentar do Setor Produtivo, e com o superintendente da FIEB, Vladson Menezes. O tema central são os projetos que afetam o setor produtivo baiano e o que se pode esperar da tramitação na Assembleia Legislativa. Acompanhe @sistema_fieb.

DUAS UNIDADES DE SAÚDE GANHAM CÂMARA DE DESINFECÇÃO Criada pelo SENAI CIMATEC com o objetivo de garantir mais proteção aos profissionais que atuam na linha de frente ao combate da Covid-19, a câmara de desinfeç̧ão foi instalada em mais duas unidades de saúde de Salvador. O Instituto Couto Maia e o Hospital Santo Antônio, das Obras Sociais Irmã Dulce (OSID), também passaram a contar com o equipamento, que já estava sendo utilizado no Hospital Espanhol.

Feita de alumínio, a câmara dispõe de uma tubulação de PVC que pulveriza uma solução de hipoclorito de sódio (água sanitária) durante a passagem de pessoas pelo equipamento. 0 profissional de saúde, ao final do seu turno de trabalho, deve passar pelo túnel, que é um corredor de 2,5 metros, ainda com o Equipamento de Proteção Individual, para que, em seguida, possa retirar o EPI com menor risco de contaminação.

A instituição continua produzindo novas câmaras de desinfecção e estuda a possibilidade de o equipamento ser utilizado em outros ambientes, como shoppings, academias e estações de metrô.

\section{PROGRAMA VAI ORIENTAR 50 MIL TRABALHADORES}

Indústrias associadas ao Sindvest Salvador passaram, nesta semana, pela Blitz contra a Covid-19, uma iniciativa do SESI Bahia

\section{R NAVÍRUS}

em parceria com sindicatos da indústria. As blitze fazem parte do Programa Juntos Contra a Covid-19, que tem como meta atingir uma população de 50 mil trabalhadores de mil empresas industriais associadas aos sindicatos da Construção, Vestuário (de Salvador e Feira de Santana) e de Mármores e Granitos, além de 550 empresas clientes do SESI VIVA +. A iniciativa também será realizada na região oeste do estado da Bahia, em parceria com a Associação Baiana dos Produtores de Algodão (Abapa).

O Programa Juntos Contra a Covid-19 tem caráter educativo junto à força de trabalho, mas também esclarece à indústria o passo a passo do protocolo, caso haja algum indício da doença no ambiente laboral. Também é feito um checklist com um plano de ação para que as empresas adotem todos cuidados necessários, desde dimensionamento de EPIs, até sugestão de layouts.

Iniciadas em Salvador, no dia 14 de abril, em parceria com o Sinduscon-BA, as blitze têm atualmente 66 canteiros de obras inscritos em todo o estado. A estimativa é que cerca de seis mil trabalhadores da indústria da construção sejam envolvidos. A expectativa do SESI e do Sinduscon é que mais empresas façam adesão à iniciativa, que deve ser efetuada junto ao sindicato.

\section{SENAI RECUPERA 75 RESPIRADORES PULMONARES}

Hospitais, unidades de Emergência e Pronto Atendimento em 40 municípios baianos já foram beneficiados pelo trabalho de recuperação de respiradores pulmonares, realizado pelo SENAI Bahia e SENAI CIMATEC. Até o dia 27.04, 75 aparelhos foram devolvidos em operação. 0 trabalho é feito por uma equipe formada por engenheiros e técnicos do SENAI e das empresas Ford e GPE, que correm contra o tempo para disponibilizar 120 aparelhos que estavam fora de uso.

\section{PRODUCÃO DE MÁSCARAS FACE SHIELD SUPERA 20 MIL} UNIDADES

Mais de 20 mil escudos faciais (face shield) foram produzidos no SENAI CIMATEC Park, em Camaçari até o dia 24.04. As máscaras face shield foram doadas para hospitais, Unidades de Pronto

Atendimento (UPA), corporaçỗes e secretarias de estado da Bahia e também para o estado do Amapá.

Equipamento de proteção individual (EPI), a máscara face shield reforça a proteção contra o coronavírus. Os escudos faciais serão utilizados por profissionais da área de saúde e de outros serviços essenciais, a exemplo dos bombeiros, durante o combate à pandemia de coronavírus.

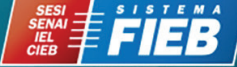

continue to provide safe and adequate food to the population.

- Sequence of work focused on research and innovation through the contemplated projects.

- Increase in the number of RT-PCR tests on employees of industries in the State of Bahia, Brazil, quickly and accurately.

- Maintenance of mechanical ventilators, production of gel alcohol and face shield masks.

- Donation of "basic baskets" and face shield masks for adults and children in the community and public hospitals in the State of Bahia, Brazil.

- Immunization of 40,000 industry workers.

- Educational campaigns to combat the coronavirus: "Bahia Contra o COVID-19" and "Amigos da FIEB".

- Fundraising and delivery of 2,400 face shields for health professionals (Around 1,000 face shields are being produced per day - Figure 10) and 630 "basic baskets" for institutions and communities in Salvador (Salvador, Bahia, Brazil).

- Creation of a disinfection tunnel for health professionals by SENAI CIMATEC (in clinical study) (Figure 11).

June 2020 (Figures 12 and 13)

- Recovery of more than 200 mechanical ventilators. 
Figure 10. Production of face shield to donnation for hospitals and communities in Bahia state (Brazil) (industrial conversion).

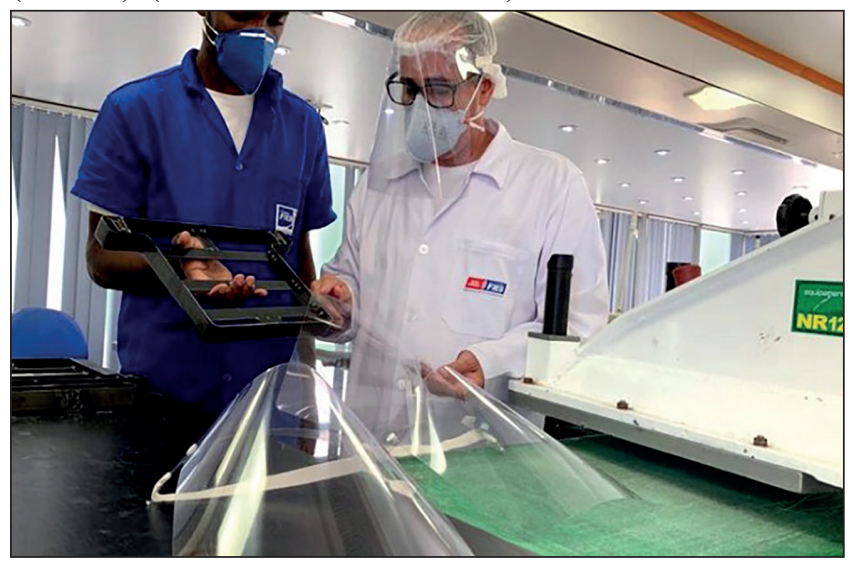

Figure 11. The tunnes of desinfection created by SENAI CIMATEC.

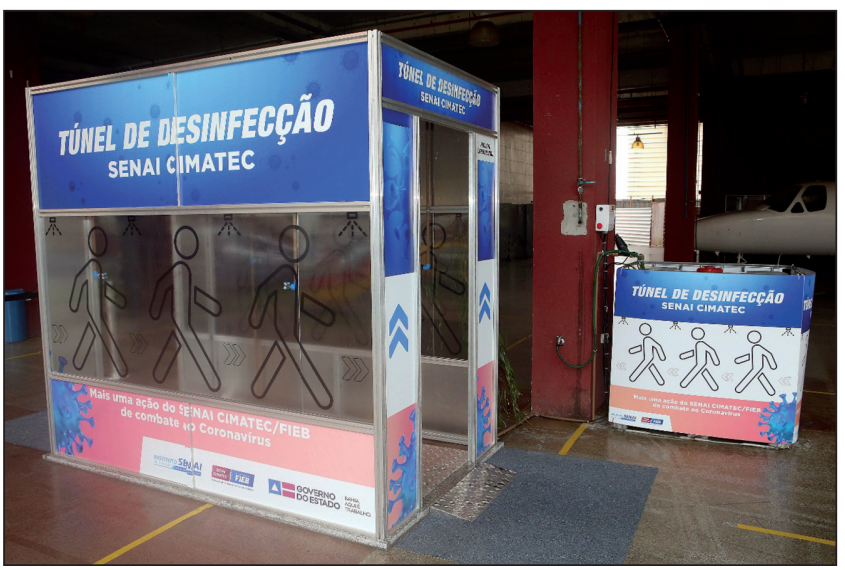

Figure 12. Folder 7 - Actions and activities of SENAI CIMATEC against COVID-19 (May 2020).

\section{Informe Sistema FIEB $n^{\circ} \mathbf{7}$}

Confira algumas ações do Sistema FIEB para o enfrentamento da crise provocada pelo novo coronavírus:

REPRESENTANTES DO GOVERNO E PREFEITURA VISITAM SENAI CIMATEC PARK E CONHECEM AÇÕES CONTRA A PANDEMIA

Uma comitiva composta pelo vice-governador do Estado, João Leão, pelo vice-prefeito, Bruno Reis, o senador Roberto Muniz, os deputados Elmar Nascimento e Eduardo Salles, e o presidente da Fecomércio, Carlos Andrade, visitou o SENAI CIMATEC Park, em Camaçari, na segunda-feira, dia 05 de maio. $\mathrm{Na}$ oportunidade, foi realizada a entrega à Prefeitura de Salvador de uma doação de 30 mil litros de álcool glicerinado a $80 \%$, para ser usado na desinfecção das unidades do sistema público de saúde da rede municipal. No total, já foram produzidos 70 mil litros de álcool glicerinado, distribuídos também para a rede estadual e entidades da sociedade civil. O grupo foi recebido pelo presidente FIEB, Ricardo Alban. Eles conheceram de perto o processo de fabricação das máscaras Face Shield (escudos faciais) - mais de 22 mil já foram produzidas - e acompanharam o trabalho dos profissionais no envase de álcool a $70 \%$, que estão sendo realizados no SENAI CIMATEC Park.

Durante a visita, também foram apresentados outros projetos estratégicos desenvolvidos pelo SENAI CIMATEC no combate à COVID-19, como a manutenção de respiradores mecânicos, que até o momento recuperou mais de 85 aparelhos; e o túnel de desinfecção, já instalado nos hospitais Espanhol e Couto Maia, em Salvador.

O presidente da FIEB, Ricardo Alban, destacou que as entidades do Sistema FIEB, convictas dos compromissos que têm com a sociedade e o poder público, foram parceiras de primeira hora no enfrentamento da pandemia. Ele reiterou a importância desta rede de apoio e mobilização social e empresarial.

\section{C.M. RAVÍRUS}

\section{INDÚSTRIA DE ELETROELETRÔNICOS ADERE À BLITZ} CONTRA A COVID-19

O SESI Bahia e o Sindicato das Indústrias de Aparelhos Elétricos, Eletrônicos, Computadores, Informática e Similares de Ilhéus e Itabuna (Sinec), realizaram na terça-feira, 05.05, ação conjunta de prevenção da Covid-19 na unidade da Daten, no município de llhéus, envolvendo 153 trabalhadores.

As equipes, compostas por engenheiros, técnicos, enfermeiro do Trabalho e técnica de Enfermagem, realizaram ações preventivas de saúde. Em toda a Bahia, as blitze vão atingir uma população de mais de 50 mil trabalhadores de empresas associadas aos sindicatos da indústria e do SESI Viva+. No segmento de eletroeletrônicos, o Sinec tem 10 empresas associadas, o que corresponde a 860 trabalhadores envolvidos.

\section{IEL PROMOVE ENCONTRO EMPRESARIAL ONLINE} A crise do novo coronavírus impôs desafios para o setor empresarial, que tem buscado se reinventar diante deste novo cenário. Para discutir este tema, o Instituto Euvaldo Lodi (IEL-BA) realiza, no próximo dia 13 de maio, um encontro empresarial online, que vai apresentar cases de empresas que estão inovando para atender as novas demandas do mercado.

Com inscrições gratuitas pela plataforma Sympla, o encontro terá como convidados o diretor regional da empresa Limpidus, Antonio Burity, e o diretor industrial da Aromarketing, Rafael Mamede, com moderação da especialista em Inovação do IEL-BA, Fabiana Carvalho. Mais informações pelo telefone (71) 3343-1530 ou pelo e-mail clubeieldenegocios@fieb.org.br.

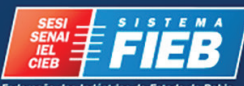


Figure 13. Folder 8 - Actions and activities of SENAI CIMATEC against COVID-19 (May 2020).

\section{Informe Sistema FIEB $\mathbf{n}^{\circ} \mathbf{8}$}

Confira algumas ações do Sistema FIEB para o

enfrentamento da crise provocada pelo novo coronavírus:

SESI REALZA BLITZ COVID-19 EM MAIS DE 100

ESTABELECIMENTOS INDUSTRIAIS

Mais de 100 estabelecimentos industriais, entre fábricas,

canteiros de obra e fazendas (agroindústria), totalizando cerca

de 10 mil trabalhadores, foram alvo das ações da Blitz contra a Covid-19 que o SESI Bahia está desenvolvendo no estado. As empresas atendidas são clientes do SESI Viva+, associadas aos sindicatos patronais e à Associação dos Produtores de Algodão (Abapa), do Oeste baiano. Até o momento, nove representações sindicais aderiram à blitz, entre eles o Sinduscon-BA, os Sindvest Salvador e Feira de Santana, o Simagran, Sindiplasba, Sinec, Sindibrita, Sindcosmetic e Sincar. Com uma equipe multiprofissional, o objetivo do SESI é reforçar recomendações sobre a higienização das mãos, o uso dos equipamentos de proteção individual, os cuidados com objetos de uso pessoal e dos espaços de uso coletivo.

Os técnicos também orientam sobre redução do contingente de pessoal na empresa, estabelecendo horários alternados de trabalho, flexibilização da jornada, home office e liberação de pessoas do grupo de risco, sempre que possível, conforme as orientações do Ministério da Economia.

\section{SESI IMUNIZOU 40 MIL TRABALHADORES CONTRA A GRIPE} NA BAHIA

Com foco na promoção da saúde, o SESI-BA realiza anualmente a Campanha de Imunização contra a Gripe. Até o dia 08.05, 40 mil trabalhadores de 260 empresas instaladas no estado da Bahia foram imunizados. A iniciativa cumpre papel importante na prevenção contra infecções pelos vírus Influenza e H1N1 e suas complicações, que afetam a saúde e produtividade dos trabalhadores. Em 2020, a campanha de imunização foi antecipada em razão da pandemia do coronavírus.

\section{SETOR EMPRESARIAL BAIANO DOA CESTAS BÁSICAS E} MÁSCARAS

Duas mil e quatrocentas máscaras foram doadas a creches de Salvador e ao Hospital Martagão Gesteira, para proteção de criancas e adultos contra o coronavírus. O material foi

adquirido com o recurso arrecadado pela Campanha Bahia Contra a Covid-19, coordenada pelo IEL-BA, em parceria com outras entidades do setor empresarial baiano.

\section{C.M. NAVÍRUS}

Realizada na plataforma de crowdfunding Bloxs, a campanha teve a participação de empresários, entidades empresariais e da sociedade baiana. Além do Hospital Martagão Gesteira, as máscaras foram doadas para as creches Lar Pérolas de Cristo, Mãe Nildete e Vó Flor, todas localizadas em Salvador. Já a campanha Amigos da FIEB, liderada pelo CIEB, entregou 630 cestas básicas para instituições e comunidades da capital baiana. Cada cesta básica contou com 14 itens alimentícios, além de materiais de limpeza, como água sanitária e detergente.

A iniciativa foi apoiada pelo IEL-BA, que operacionalizou a arrecadação do recurso, além da aquisição e distribuição dos itens para doação. A campanha beneficiou o Centro Cultural Oficina Reciclável, a Creche Escola Mãe Nildete, a Creche Bezerra de Menezes, o Instituto de Esporte, Cidadania e Inclusão Social, o Movimento Mulheres do Subúrbio Ginga, além de famílias dos bairros de Capelinha de São Caetano e Bom Juá.

\section{HOSPITAIS DA CAPITAL E DO INTERIOR JÁ CONTAM COM} TÚNEIS DE DESINFECCÃO

Três túneis de desinfecção desenvolvidos pelo SENAI CIMATEC foram instalados no dia 12.05, nos hospitais do Subúrbio, Ernesto Simões Filho e Martagão Gesteira, em Salvador. Com os equipamentos, as unidades passam a ofertar mais segurança para os profissionais de saúde que atendem pacientes diagnosticados com Covid-19.

No total, oito hospitais da Bahia já contam com os túneis de desinfecção. No interior, os equipamentos foram instalados nos hospitais Costa do Cacau, em Ilhéus, e Calixto Midlej Filho, em Itabuna. A estimativa é que outras unidades de saúde do estado também recebam o equipamento.

O túnel produzido pelo CIMATEC, sob a supervisão do infectologista Roberto Badaró, pesquisador chefe do Instituto SENAI de Tecnologia da Saúde.
Figure 14. New technologies by SENAI CIMATEC against COVID-19.

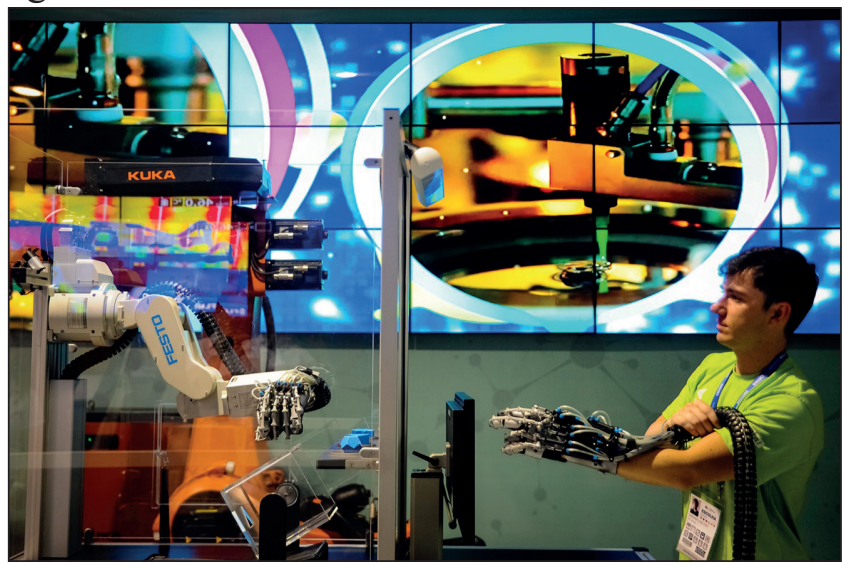

- Educational robotics in the fight against COVID-19 (Figure 14).

- Donation of educational licenses to SENAI CIMATEC students by companies.

- Expansion of COVID-19 tests for industries in Bahia (50,000 tests for screening in industries in the State of Bahia, Brazil, providing the rapid IgM / IgG test) (Figure 15).

- Expansion of RT PCR testing in Bahia industries.

- Expansion of the recovery of mechanical ventilators.

- Maintenance of gel alcohol packaging for industries. 
Figure 15. Rapid test (IgG/IgM - sorologic test).

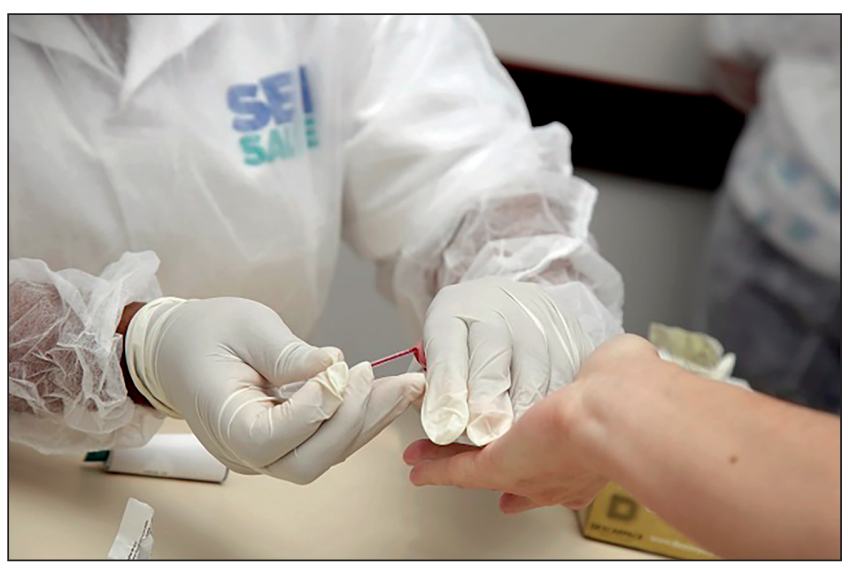

- Maintenance of the production of face shield masks for donations in communities and hospitals in the State of Bahia, Brazil.

\section{References}

1. Mulder N. How the coronavirus war economy will change the United States and the world forever. Foreign Office 2020. https://foreignpolicy.com/2020/03/26/the-coronavirus-wareconomy-will-change-the-world/.

2. KPMG. European Union - Government and institution measures in response to COVID-19. 24 April 2020. https:// home.kpmg/xx/en/home/insights/2020/04/european-uniongovernment-and-institution-measures-inresponse-to-covid. html.

3. European Commission. COVID-19: Commission sets out European coordinated response to counter the economic impact of the coronavirus. Brussels: European Commission Press Release 2020.

4. Castaneda-Navarrete J, Leal-Ayala D, López-Gómez C, Palladino M. COVID-19: International manufacturing policy responses. Institute for Manufacturing (IfM), University of Cambridge, 2020;April. https://www.ifm.eng.cam.ac.uk/ uploads/ECS/Policy_Links/2020-04-07-COVID19A.pdf.

5. OCDE - Tax and fiscal policy in response to the coronavirus crisis. Paris: OCDE, April 2020. https://www.oecd.org/tax/taxpolicy/tax-and-fiscal-policy-in-response-to-the-coronaviruscrisis-strengthening-confidence-and-resilience.htm.

6. UK Government. UK government ventilator challenge.https:// www.gov.uk/government/topical-events/coronavirus-ukgovernment-ventilator-challenge.

7. UK Government. Update on the ventilator challenge. 2020. https://www.gov.uk/government/news/update-on-theventilator-challenge.
8. Dzhanova Y. Trump compelled these companies to make critical supplies, but most of them were already Doing it. CNBC 2020. https://www.cnbc.com/2020/04/03/coronavirustrump-used-defense-production-act-on-these-companies-sofar.html.

9. Heinzmann FBT. From perfume to hand sanitiser, TVs to face masks: how companies are changing track to fight COVID-19. World Economic Forum 2020. https://www.weforum.org/ agenda/2020/03/from-perfume-to-hand-sanitiser-tvs-toface-masks-how-companies-are-changing-track-to-fightCOVID-19/.

10. Ventilator Challenge UK Consortium. https://www. ventilatorchallengeuk.com/.

11. UK Government. Update on the ventilator challenge. 2020; Apr. https://www.gov.uk/government/news/update-on-the-ventilatorchallenge.

12. Department of Health and Human Services. https://www.hhs. gov/news.

13. Machado AP. Abimaq cria grupo para produzir produtos médicos. Valor Econômico 2020; Apr. https://valor.globo. com/empresas/noticia/2020/04/23/abimaq-cria-grupo-paraproduzir-produtos-medicos.ghtml.

14. O Estado de São Paulo.Produção local de componentes cresce. 2020; May.

15. Shibata N. Japan's cosmetics makers and distillers rush to make sanitizers, Nikkei Asian Review 2020;April 23.https:// asia.nikkei.com/Spotlight/Coronavirus/Japan-s-cosmeticsmakers-and-distillers-rush-to-make-sanitizers.

16. Nogueira I. Fábricas de roupa íntima passam a produzir máscara contra COVID-19 no Rio. Folha de São Paulo, Cotidiano 2020; Apr. https://www1.folha.uol.com.br/cotidiano/2020/04/ fabricas-de-roupa-intima-passam-a-produzir-mascara-contraCOVID-19-no-rio.shtml.

17. Stebbins S, Suneson G. Coronavirus relief: 30 companies helping Americans fight COVID-19. USA Today 2020;Apr. https://www.usatoday.com/story/money/2020/04/21/ companies-that-are-helping.

18. Deboutte G. Le secret de l'Allemagne pour réaliser 500000 tests du COVID-19 par semain. Usine Nouvelle 2020.https://www. usinenouvelle.com/editorial/le-secret-de-1-allemagne-pourrealiser-500-000-tests-du-COVID-19-par-semaine.N946526.

19. López-Gómez C, Corsini L, Leal-Ayala D, Fokeer S. COVID-19 critical supplies: The manufacturing repurposing challenge. Reino Unido 2020;Apr. https://www.unido.org/news/COVID19-critical-supplies-manufacturing-repurposing-challenge.

20. Kliff S, Satariano S, Silver-Greenberg J, Kulish N. There aren't enough ventilators to cope with the coronavirus. New York Times 2020. https://www.nytimes.com/2020/03/18/business/ coronavirus-ventilator-shortage.html.

21. Bahl C, Suman R, Vaishe A. Industry 4.0 technologies and their applications in fighting COVID-19 pandemic. Diabetes Metab Syndr 2020;14(4):419-422. Doi: 10.1016/j.dsx.2020.04.032.

22. Walcott DA, Global Shaper, Kingston Hub. The European sting with the World Economic Forum. UK 2020 